\title{
Gaining a global perspective on public health through an international student nurse collaboration
}

\author{
Donna Greenwood*1, Michelle Honey ${ }^{2}$, Anne Clancy ${ }^{3}$ \\ ${ }^{1}$ Carroll College, Helena, MT, United States \\ ${ }^{2}$ University of Auckland, Auckland, New Zealand \\ ${ }^{3}$ UiT The Norwegian University of the Arctic Campus, Harstad, Norway
}

Received: February 15, 2016

DOI: $10.5430 /$ jnep.v6n8p123
Accepted: March 21, 2016

URL: http://dx.doi.org/10.5430/jnep.v6n8p123

Online Published: April 6, 2016

\section{Abstract}

Recognizing that nursing practice worldwide will be strongly influenced and shaped by new technologies and their applications, nurse educators from three countries, the United States, New Zealand and Norway collaborated and designed a learning and international networking opportunity for student nurses. The purpose of the project was to enhance awareness of global health, increase student nurses knowledge of public health nursing practices and needs in other countries and to promote solidarity and opportunities for collaboration across boundaries. Nursing students from each country used video conferencing in small groups to meet peers virtually as part of the public health nursing component of their undergraduate course. Experience in collaborating and increased awareness of the differences and similarities of nursing in different contexts was appreciated by the students and the recommendation is that despite some small technical and practical issues, this initiative for international collaboration between student nurses should continue, and other Schools of Nursing could follow this model.

Key Words: Nursing, Baccalaureate, Public health, Video conferencing, International

\section{INTRODUCTION}

The advances in science and technology that have influenced the political, economic, social and environmental landscapes of the world have contributed to the need for a new and expanded paradigm of nursing collaboration and partnership. International travel and information and communication technologies (ICT) influence nursing and health care delivery around the world. The term for the experience of shrinking the geographical distances of the world resulting in seeing a shared society rather than disparate countries is the term 'global village'. ${ }^{[1]}$ Nurses require the vision and foresight to anticipate trends and needs in the global village and today's student nurses need to be prepared to be future nurse leaders with the capability to work across borders and cultures in the best interests of global health. ${ }^{[2]}$ This case report describes an educational initiative between three countries where students used video conferencing to collaborate and discuss public health issues from their part of the world.

\section{INTERNATIONAL COLLABORATION}

Working across international boundaries and cultures can promote the exchange of knowledge and increase a sense of global responsibility and solidarity. The idea of international nursing collaboration is not new. Since 1899 nurses have formally organized global networks through such organizations as the International Council of Nurses, who now represent

\footnotetext{
*Correspondence: Donna Greenwood; Email: dgreenwo@ carroll.edu; Address: Department of Nursing, Carroll College, 1601 N. Benton, Helena, MT 59625, United States.
} 
16 million nurses from 130 national nursing associations. ${ }^{[3]}$ In relation specifically to public health, The Global Network of Public Health Nurses ${ }^{[4]}$ was formed during the 2013 International Public Health Nursing Conference in Ireland.

Internationalization of higher education has increased in the past two decades, and while it is driven by commercial interest (the need to make money, especially in times of reduced funding), the use of ICT has eliminated barriers of distance and time, thereby attracting increasing numbers of students. ${ }^{[5]}$ Literature also indicates examples of international collaboration within nursing education. ${ }^{[6-11]}$ Nursing has followed this trend of internationalizing education and this has meant extension from the more traditional role of attracting international students and study abroad programs, to supporting faculty and providing higher education in areas where it may not otherwise be available,${ }^{[8,11]}$ and to extend learning opportunities. ${ }^{[10]}$ Extension of learning provides examples of international collaboration often linked to specific content, such as cultural awareness, ${ }^{[6]}$ ethics, ${ }^{[10]}$ evidence based practice ${ }^{[7]}$ or to provide a global perspective. ${ }^{[9]}$

\subsection{Technology to support collaboration}

Technology provides tools which aid communication and collaboration. These include the use of email and Web 2.0 internet applications, such as wikis and blogs, for asynchronous communication. Synchronous communication using telephones could use a landline, mobile or Wi-Fi connection, or alternatively internet based real time communication. ${ }^{[12,13]}$ 'Smart phones' provide the advantages of mobile communication using either a mobile or internet connection. Additionally, there are options for audio and video conferencing, using phone or internet connections. Language translation software aids communication, when language is a barrier. ${ }^{[14]}$

Technology can be used to augment more traditional modes of teaching. For example, Leppa and Terry ${ }^{[10]}$ describe using on-line discussion between nurses in the United Kingdom (UK) and United States (U.S.) in conjunction with combinations of classroom-based teaching and international visits by students and teachers. Daley, Spalla, Arndt \& Warnes ${ }^{[15]}$ utilized video conferencing within the classroom to develop peer partnerships and leadership skills between students in a Midwestern US college and students in the UK, with faculty serving in a supportive role to facilitate conversation and clarify concepts as necessary. A further example of international collaboration, facilitated by technology, is provided by Veltman, Connor, Honey, Diener \& Bodily ${ }^{[16]}$ in describing a teaching project utilizing the virtual world, "Second Life".

Nurses in practice are also capitalizing upon the opportunity for international collaboration and education, such as the example of utilizing video conferencing technologies 124 routinely between nurses at Johns Hopkins Hospital in the US and nursing staff in Abu Dhabi for continuing nursing education. ${ }^{[17]}$

\subsection{Our case of international student collaboration}

This case reports on a collaborative project which aimed to enhance awareness of global health, increase student nurses' knowledge of public health nursing practices and needs in other countries, and to promote ongoing professional collaboration. Nurse educators from three countries, the US, New Zealand (NZ) and Norway joined in an exploratory collaboration that incorporated video conferencing between student nurses in each country; driven by public health awareness and an understanding that nurses need competency in international communication for their future practice. E-mail and video conferencing over a period of six months facilitated development of a plan on how an international learning experience related to community health nursing using ICT could be incorporated into the students' respective courses. Consideration was made for the differences in nursing curricula, academic calendars and time zones. Key considerations for how each country incorporated the project are shown in Table 1 , which also identifies the number of students and which year of their undergraduate nursing program they were in.

The authors, all nurse educators, utilizing video conferencing and e-mail, discussed details and planning for this project, which included: size of groups, group composition, scheduling of video-conferences, the role of group coordinators and how the video conferences might develop. The approach decided on was that the students would have the video conferences without faculty present, in the hope that this would encourage better peer-to-peer communication. Taking into consideration the diversity of cultures, differences in student level in their respective nursing programs and possible language issues, the three educators developed a common set of guidelines to direct the students.

The collaboration period ran between February and April 2013. Ethical concerns have been taken into consideration. No name register was established. According to the criteria of the Norwegian Centre of Research Data the study can be published as the data is de-identified and is severed from the data contributors. Student participation was voluntary. Twenty-five students from the three countries volunteered to participate (see Table 1). Students were divided into three groups with three or four students from NZ, three from the US and two from Norway in each group. One student from each country served as the country coordinator for their group. The coordinator's role was to be the contact person and to coordinate with the other students from their country in their group and arrange the timing of video conferencing with the other coordinators.

ISSN 1925-4040 E-ISSN 1925-4059 
Table 1. Incorporating the collaboration in the curricula

\begin{tabular}{|c|c|c|c|}
\hline Country & Incorporating into curriculum & $\begin{array}{l}\text { Number of } \\
\text { students }\end{array}$ & Year of students \\
\hline \multirow{4}{*}{ United States } & Developed a one credit special topic class with three goals: & \multirow{4}{*}{9} & \multirow{4}{*}{$\begin{array}{l}4^{\text {th }} \text { year ( } 6 \text { students) } \\
2^{\text {nd }} \text { year ( } 3 \text { students) }\end{array}$} \\
\hline & 1) Student nurse exposure to world cultures & & \\
\hline & $\begin{array}{l}\text { Develop leadership skills to transform health care from an } \\
\text { illness model to a prevention model of care }\end{array}$ & & \\
\hline & $\begin{array}{l}\text { Create international nurse networks and partnerships for } \\
\text { ongoing professional communication }\end{array}$ & & \\
\hline Norway & $\begin{array}{l}\text { 1) Incorporated a global health focus into an existing } \\
\text { mandatory module on public health for first year students } \\
\text { 2) Recruited third year students, who participated } \\
\text { voluntarily. Post project presentation was integrated as } \\
\text { part of mandatory pedagogical assignments }\end{array}$ & 6 & $\begin{array}{l}\left.1^{\text {st }} \text { year ( } 4 \text { students }\right) \\
3^{\text {rd }} \text { year (2 students) }\end{array}$ \\
\hline New Zealand & $\begin{array}{l}\text { Called for volunteers from an existing class during their } \\
\text { Community Health module }\end{array}$ & 10 & $3^{\text {rd }}$ year \\
\hline
\end{tabular}

Based on practical considerations it was decided that three video-conferences utilizing video conferencing of approximately one hour were to be held over the period of three months. General guidelines and topics for discussion were given to the students by e-mail and in face-to-face preparatory meetings (see Table 2). The topics for discussion were designed on the assumption that having a focus would provide direction and enhance communication, with the idea that discussion might diversify once students became more comfortable with each other. In order to prepare the students and alleviate language difficulties, the Norwegian nurse educator had preparatory meetings in English with the Norwegian students, as the language for the international collaboration was English. The dates for video conferencing were determined by the students based on their schedules. Recommendations were made for specific times to eliminate the need for any students to be awake in the middle of the night. The three faculty members collaborated as needed via email and video conferencing and addressed student questions that arose during the project period.

Table 2. Video-conference discussion topics

\begin{tabular}{ll}
\hline Meeting & Discussion Topic \\
\hline 1 & $\begin{array}{l}\text { Introduce group members } \\
\text { Describe nursing education in each country } \\
\text { Define public health nursing in each country } \\
2\end{array}$ \\
$\begin{array}{l}\text { Describe the top two or three public health issues in each } \\
\text { country }\end{array}$ \\
$\begin{array}{l}\text { Discuss the present and future health issues that nurses in } \\
\text { the global village will need to address }\end{array}$ \\
\hline
\end{tabular}

When volunteering to participate, students were informed that feedback would be sought as part of evaluating the project. Students were requested to answer four questions: "What did you get out of meeting with other student nurses

Published by Sciedu Press and collaborating internationally?" "What interesting points were raised?" "What have you learned?" "Should we offer this again?" Both verbal and emailed responses were received. All feedback from students was anonymized and content analyzed for themes. Patton (p. 452) ${ }^{[18]}$ refers to content analysis as "any qualitative data reduction and sense making effort that attempts to identify the data's core consistencies and meanings". The inductive content analysis of student feedback started with a holistic reading of the material; then words, phrases and paragraphs that conveyed the same meanings were highlighted and themes noted.

Maintaining the welfare and integrity of the students was important for the authors. Keeping the interests of the students at the forefront entailed giving careful consideration to the following: importance of information, voluntary participation and confidentiality. Findings are presented in a general way in order to protect the identity of the students. Students in all countries were given an oral and written explanation of the project. No data register was created and the data was not electronically processed. Additionally, due to the group nature of this collaborative project, the opportunity to emphasize confidentiality and privacy was taken into consideration and students were referred to their respective nursing standards. For example, the US students were directed to the National Council of State Boards of Nursing (NCSBN) White Paper: A nurse's guide to the use of social media. ${ }^{[19]}$

\section{Findings}

Analysis of the student feedback revealed the following themes: Personal development, differences and similarities, public health concerns, and technological issues. The findings are presented under these headings with illustrative quotes as indicated. 


\subsection{Personal development}

Although students were nervous before the start about how the conversation would flow, they found participating in the video conferencing with other student nurses beneficial to their personal growth and socialization as a nurse. This is summarized in a student comment: "The international nursing collaboration has enriched our education and helped us to broaden our perspectives." The students spoke about feeling empowered. They described the process as "a journey" that they hoped would continue and that they could meet the students later in their careers.

The personal impact of being involved in collaboration between students in three countries is captured in the following which came from students in each country: "This has been an incredible life changing experience! It has made the world feel like it's a smaller place", and "I really enjoyed learning about each country's culture" and "I learned that education on cultural differences is very important, especially respect of other cultures. The more you understand the people you are taking care of, the greater care you are able to provide".

\subsection{Similarities and differences}

Some students identified that they "don't normally communicate with anyone outside their country"; therefore, participating in this project broadened their views. For example, one student stated, "it was interesting to have a different perspective on nursing and nursing programs". Students realized that they weren't so different after all: "Awesome seeing how similar we are as students". Learning about these similarities made it easier for friendships to develop: "It was so nice to make new friends in [different countries] that may continue beyond this experience." Examples of how students perceived the differences and similarities between the countries included: "It's amazing how similar, yet how different all three of our countries are" and "It's so cool how similar we are but all have unique differences". For example, the students compared their nursing curricula and found that each program was organized differently, yet the content also contained many similarities.

\subsection{Global public health issues}

The collaboration was a positive learning experience: "I believe it helped me learn so much about nursing around the globe and public health in general". The students discussed general public health issues and issues specifically related to indigenous populations. Public health concerns shared from each country had some commonalities, with students saying, "It is amazing how many health issues not only cross borders but oceans into different nations" and that the other countries "also have indigenous populations who experience many of the same health issues and have many of the same issues as our [native] populations".

The students became aware that all countries had problems related to diabetes, obesity and cardiovascular diseases. The students also discussed mental health issues and the rise in psychological problems and lack of services. They spoke of how their respective countries dealt with public health problems and noted differences in each country's welfare systems. They discussed future challenges related to antibiotic resistance, which was an issue in all countries. As one student said, "In a way it helps to see the bigger picture, that it is not just about one nation trying to fix itself. We are a team, all nations around the world, and we are trying to help the world become a healthier place and prevent disease and harm."

\subsection{Practical challenges}

The practical issues that students raised have been collated and fall into two categories: time differences and technical problems. Students reported difficulties finding dates and times that would work for the students in each of the countries when students have different schedules, clinical work and time differences. The difficulties in timing were compounded by daylight saving, with a student stating: "We didn't think about daylight savings time changes and that they would be different around the world." Another issue was "technology difficulties". This ranged from an initial lack of awareness of using video conferencing and having three or more connections if students were not together, to some groups finding issues with the connection, such as voice lag, poor video or the connection dropping (disconnecting). However, students generally felt it was worth persevering as, "I think we have all expanded our views and greatly benefited from it."

\section{Discussion}

Overall, incorporating an opportunity for student nurses to participate in an international collaboration using technologymediated communication was a positive learning experience and enhanced their understanding of global public health issues. Pirkey, Levey, Newberry, Guthman and Hansen ${ }^{\text {[20] }}$ identified that public health nurses are concerned about new graduate nurses' competence for working with diverse populations. The students' interchanges using video conferencing provided an ideal context to consolidate core public health concepts taught in their respective classes. In this project, students' dialogue related to indigenous populations, poverty, communicable disease and global health threats may reinforce learning related to public health nursing principles including the need for respect and appreciation for other 
cultures. This knowledge addresses the concerns raised by Pirkey et al. ${ }^{[20]}$ and also encompasses the QUAD Council competencies for public health nurses. ${ }^{[21]}$ The American Nurses Association Scope and Standards of Public Health Nursing ${ }^{[22]}$ and the cultural competency behaviors identified by the American Association of Colleges of Nursing. [23] Additionally, international collaboration can provide opportunities for cross-cultural communication and present other perspectives on global health issues, ${ }^{[2]}$ and this collaborative project demonstrates this.

The video conferences of this project promoted the students' personal development as they became aware of other contexts. Benner, Sutphen, Leonard \& Day ${ }^{[24]}$ stress the need for promoting nursing students' personal development and use of contextualized knowledge, and this project appeared to do this, though this was not specifically evaluated, but is an area for future research. The American Association of Colleges of Nurses (AACN) has identified five values that are essential for the practice of professional nursing: human dignity, integrity, autonomy, respect and social justice. ${ }^{[25]}$ Students participating in this project directly addressed human dignity, respect and social justice; and indirectly addressed the values of integrity and autonomy. The discussion of health disparities, indigenous populations, the differences in the organization of the health care systems, differences in the respective countries' governance and differences in nursing education challenged students' existing paradigms and promoted the internalization of professional nursing values.

Changes in science and technology have transformed nursing practice and nursing education, necessitating the need for varied pedagogical methods. ${ }^{[24]}$ More traditional modes of student international collaboration and study abroad programs tend to involve only a few students, ${ }^{[8,11]}$ often because of travel, finance and time constraints. Using technology to provide an opportunity for students to collaborate as part of their undergraduate nursing courses has the advantages of being affordable, accessible to a larger number of students, and it can be incorporated into curricula, so that it becomes a part of the learning expectations for students.

The relationship and collaboration between the nurse educators was an important foundation for this project, which aligns with other work involving international collaboration. ${ }^{[7,16]}$ As the nurse educators work in different educational settings, an understanding of each other's context, courses and institutional factors was needed, along with a willingness to collaborate. An example of this willingness to find common ground is shown when the nurse educators identified a common philosophy that they would not be part of the student conversations to ensure that students felt free

Published by Sciedu Press to engage in open dialogue, which was in contrast to the approach of Daley et al. ${ }^{[15]}$

Technology does not totally remove access issues ${ }^{[10]}$ because of difficulties that can arise and this collaborative project experienced a number of small, frustrating technical issues. Technical challenges in relation to international collaboration are known. ${ }^{[2,7]}$ However, using technology for collaboration allows interaction that might otherwise have to rely on faceto-face contact, which may not be possible. ${ }^{[16]}$ While others have found that a three way collaboration was less successful, ${ }^{[7]}$ there is also evidence that collaboration even between only two organizations can be problematic. ${ }^{[2]}$

The scope of the project is small; however, it does illustrate what students gained. Having now confirmed that student nurse peer-to-peer collaboration using video conferencing is acceptable to students and effective in supporting them gaining a global perspective of public health issues, the collaboration can now be extended. Moreover, students participating in this collaboration report that they have continued communicating with their international partners on Facebook, indicating relationships extending beyond their Schools of Nursing. The use of video conferencing for synchronous communication allowed for audio and video communication and a real sense of connection to develop.

\section{LESSONS LEARNED}

This project provides useful recommendations for others considering implementing a similar international collaboration.

(1) Foremost is the need to plan for teaching and learning to ensure international collaboration meets course outcomes.

(2) International dialogue for student nurses can support learning and achievement of course outcomes but it needs to be included in a structured manner.

(3) Video conferencing which supports both audio and visual communication worked well to develop relationships.

(4) Research and review video conferencing services to determine the best product for student use, looking at low cost and reliability.

(5) The scheduling of video conferencing across multiple time zones and academic calendars is challenging and may require support from faculty.

Based on the experience of this collaborative project the authors would urge nurse educators to collaborate with international colleagues and develop opportunities for students to collaborate within their existing courses as a way to enhance a global perspective on health. 


\section{Conclusion}

The socialization of future nurses as visionary global leaders must begin in nursing education. In this digital age many students possess skills in the use of social media networks in their personal lives; therefore, incorporating video conferencing as a part of the student's educational experience is a logical step forward. Further, nurse educators can utilize international dialogue experiences to increase global awareness.

\section{CONFlicts OF InTEREST Disclosure}

The authors declare that there are no competing interests.

\section{REFERENCES}

[1] Bettcher D, Lee K. Globalisation and public health. Journal of Epidemiology and Community Health. 2002; 56(1): 8-17. PMid:11801614. http://dx.doi.org/10.1136/jech.56.1.8

[2] Garnera BL, Metcalfe SE, Hallyburton A. International collaboration: A concept model to engage nursing leaders and promote global nursing education partnerships. Nurse Education in Practice. 2009; 9(2): 102-108. PMid:19059008. http://dx.doi.org/10.1016/j.nep r.2008.10.011

[3] International Council of Nurses. About ICN. 2003. Available from http://www.icn.ch/about-icn/about-icn

[4] Global Network of Public Health Nurses. Welcome. 2015. Available from: www.gnphn.com

[5] Altbach PG, Knight J. The internationalization of higher education: Motivations and realities. Journal of Studies in International Education. 2007; 11(3-4): 290-305. http://dx.doi.org/10.1177/1 028315307303542

[6] Bentley R, Ellison KJ. Increasing cultural competence in nursing through international service-learning experiences. Nurse Educator. 2007; 32(5): 207-211. PMid:17828021. http://dx . doi .org/10. 1097/01. NNE.0000289385.14007.b4

[7] Honey MLL, Doherty I, McKillop AM. Factors for a successful international collaboration to develop an evidence based practice e-learning course. In J. Luca, \& E. R. Weippl (Eds.), ED-MEDIA 2008: World Conference on Educational Multimedia, Hypermedia \& Telecommunications (pp. 2597-2602). Vienna, Austria, June 30 July 4.

[8] Ketefian S, Davidson P, Daly J, et al. Issues and challenges in international doctoral education in nursing. Nursing and Health Sciences 2005; 7(3): 150-156. PMid:16083477. http://dx.doi.org/10. 1111/j.1442-2018.2005.00240.x

[9] Leh SK, Waldspurger Robb WJ, Albin B. The student/faculty international exchange: Responding to the challenge of developing a global perspective in nursing education. Nursing Education Perspectives. 2004; 25(2): 86-90. PMid:15124513.

[10] Leppa CJ, Terry LM. Reflective practice in nursing ethics education: International collaboration. Journal of Advanced Nursing. 2004 48(2): 195-202. PMid:15369500. http://dx.doi.org/10.1111 /j.1365-2648.2004.03187.x

[11] Sherwood G, Liu H. International collaboration for developing graduate education in China. Nursing Outlook. 2005; 53(1): 1520. PMid:15761395. http://dx.doi.org/10.1016/j.outlook .2004 .08 .006

[12] Faubert DS. Education Technology Center: Technologies of distance education. 2010. Available from: https://wiki.uiowa.edu/dis play/edtech/technologies+of+distance+education
[13] Sappingtonk R. Using technology for communication and training. 2013. Available from: http://www.slideshare.net/sapping tonkr/communicating-with-technology

[14] Aiken M, Wang J, Gu L, et al. An exploratory study of how technology supports communication in multilingual groups. In E. Kock (Ed.), Interdisciplinary Applications of Electronic Collaboration Approaches and Technologies (pp. 17-29). Hershey, PA: IGI Global. 2013. http://dx.doi.org/10.4018/978-1-4666-202 $0-9 . \operatorname{ch} 002$

[15] Daley L, Spalla T, Arndt MJ, et al. Videoconferencing and web-based conferencing to enhance learning communities. Journal of Nursing Education. 2008; 47(2): 78-81. http://dx.doi .org/10.3928/0 1484834-20080201-06

[16] Veltman M, Connor K, Honey M, et al. Collaborative practice through simulations in a multiuser virtual environment. CIN: Computers, Informatics, Nursing. 2012; 30(2): 63-67. http://dx . doi .org/10. $1097 /$ NXN . Ob013e31824a8b89

[17] Proch R. Going global with nursing practice. Johns Hopkins Nursing, Fall/Winter. 2011. Available from: http://magazine.nursing.jhu.edu/2011/12/going-g lobal-with-nursing-practice-2/

[18] Patton MQ. Qualitative research \& evaluation methods (3rd ed.). Thousand Oaks, CA: Sage Publications. 2002.

[19] National Council of State Boards of Nursing. White paper: a nurse's guide to the use of social media. 2011. Available from: https ://www.ncsbn.org/Social_Media.pdf

[20] Pirkey JM, Levey JA, Newberry SM, et al. Videoconferencing expands nursing students' cultural realm. Journal of Nursing Education. 2012; 51(10): 587-590.

[21] Quad Council of Public Health Nursing Organizations. QUAD Council of Public Health Nursing Competencies. 2011. Available from: http://www.resourcenter.net/images/ACHNE/File s/QuadCouncilCompetenciesForPublicHealthNurses_Sum mer2011.pdf

[22] American Nurses Association. Public Health Nursing: Scope \& Standards of Practice, (2nd ed). Silver Spring, MD: The American Nurses Association. 2013.

[23] American Association of Colleges of Nursing. Cultural competency in baccalaureate nursing education. 2014. Available from: http://www.aacn.nche.edu/education-resources/c ultural-competency

[24] Benner P, Sutphen M, Leonard V, et al. Educating nurses: A call for radical transformation. San Francisco, CA: Jossey-Bass. 2009.

[25] American Association of Colleges of Nursing. The essentials of baccalaureate education for professional nursing practice. 2008. Available from: http://www.aacn.nche.edu/education-resourc es/baccessentials08.pdf 